\title{
Diagnosis of Advanced Disease in Cases of Colorectal Cancer in a Developing Country
}

\author{
Ricella Maria Souza da Silva ${ }^{1}$ \\ ${ }^{1}$ Hospital Universitário Lauro Wanderley, Anatomy Laboratory Unit Pathology, \\ Universidade Federal da Paraíba, João Pessoa, Paraíba, Brazil \\ 2 Faculty of Medicine, Centro Universitário de João Pessoa, João \\ Pessoa, Paraíba, Brazil \\ ${ }^{3}$ Faculty of Medicine, Department of Pathology, Universidade Federal \\ Fluminense, Niterói, Rio de Janeiro, Brazil \\ J Coloproctol 2022;42(1):25-31.
}

Polyana Maria Cruz Collaço 2 (i)

Karin S. Cunha ${ }^{3}$ (1)

Eliane Pedra Dias 30

\begin{abstract}
Address for correspondence Ricella Maria Souza da Silva, MD, PhD, Universidade Federal da Paraíba, Rua Tab. Stanislau Eloy, 585, João Pessoa, Paraíba, Brazil, 58050-585 (e-mail: ricellasouza@gmail.com).
\end{abstract}

\begin{abstract}
Keywords

- colorectal cancer

- pathological features

- neoplasm staging

- advanced disease

Objectives Colorectal cancer (CRC) is the second leading cause of cancer death in the world, with survival correlated with the extension of the disease at diagnosis. In many low-/middle-income countries, the incidence of CRC is increasing rapidly, while decreasing rates are observed in high-income countries. We evaluated the anatomopathological profile of 390 patients diagnosed with CRC who underwent surgical resection, over a six-year period, in the state of Paraíba, northeastern Brazil.

Results Adenocarcinomas accounted for $98 \%$ of the cases of primary colorectal tumors, and $53.8 \%$ occurred in female patients. The average age of the sample was 63.5 years, with $81.8 \%$ of individuals older than 50 years of age and $6.4 \%$ under 40 years of age. The most frequent location was the distal colon; PT3 status was found in $71 \%$ of patients, and pT4 status, in $14.4 \%$. Angiolymphatic and lymph-node involvements were found in $48.7 \%$ and $46.9 \%$ of the cases respectively. Distant metastasis was observed in $9.2 \%$ of the patients. Advanced disease was diagnosed in almost half of the patients (48.1\%). The women in the sample had poorly-differentiated adenocarcinomas $(p=0.043)$. Patients under 60 years of age had a higher rate of lymph-node metastasis $(p=0.044)$. Tumor budding was present in $27.2 \%$ of the cases, and it was associated with the female gender, the mucinous histological type, and the depth of invasion (pT3 and pT4).

Conclusions We conclude that the diagnosis of advanced disease in CRC is still a reality, with a high occurrence of aggressive prognostic factors, which results in a worse prognosis.
\end{abstract}

\section{Introduction}

Colorectal cancer (CRC) is the most common malignant neoplasm of the gastrointestinal tract, and is among the most common cancers in the Western world, being the third most commonly diagnosed. ${ }^{1}$ Its incidence rates vary by more than ten-fold worldwide, with higher incidence in developed countries than underdeveloped countries. ${ }^{2,3}$ Due to the increased incidence and mortality observed in recent decades, as well as the costs associated with diagnosis and treatment, this cancer has become a major public health problem in many countries. ${ }^{4}$ received

April 2, 2021

accepted after revision

June 15, 2021

published online

November 18, 2021
DOI https://doi.org/

10.1055/s-0041-1736517.

ISSN 2237-9363.

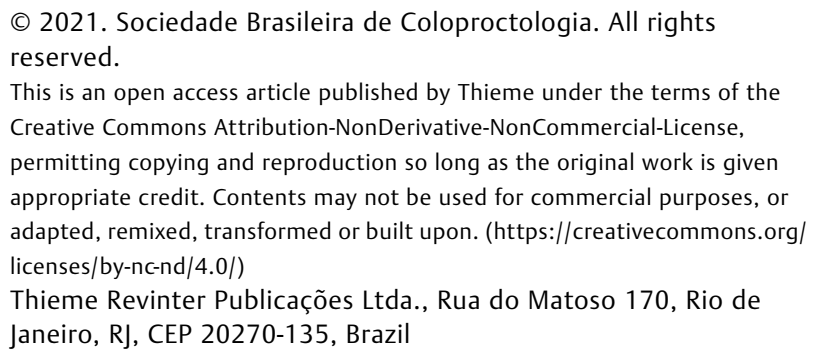


Colorectal cancer is considered the second leading cause of cancer death in both genders, ${ }^{3}$ and the most common cause of cancer-related death among non-smokers, ${ }^{5}$ with an increase of more than $27.8 \%$ in the mortality rate related to population growth and aging. ${ }^{5}$ Globally, there is a reduction in mortality in Western Europe, North America, and Japan, and an increase in developing countries. ${ }^{6,7}$ In a developing and emerging country such as Brazil, 20.540 new cases of colon and rectal cancers in men and 20.470 in women for each year of the 2020-2022 triennium have been estimated. These values correspond to an estimated risk of 19.64 new cases per 100 thousand men and 19.03 per 100 thousand women. ${ }^{8}$

This neoplasm is the second most diagnosed cancer in women and the third in men. ${ }^{2,8-10}$ More than $90 \%$ of CRC cases occur in people older than 50 years of age, with an overall age at diagnosis of 65 years. ${ }^{4,11}$ In the European Union and the United States, between $2 \%$ and $8 \%$ of cases occur in people under the age of $40 .^{12}$ In this same age group, in developing countries, the occurrence of CRC is much higher, ranging from $15 \%$ to $35 \%{ }^{13}$ Overall, there is a wide variation in the frequency of CRC in the population under 50 years of age, ranging from $1.3 \%$ to $37 \%$, and the highest values were found among the Asian population. ${ }^{4}$

Most (90\%) cases of CRC are adenocarcinomas, and survival is mainly correlated with the extension of the disease at diagnosis. ${ }^{2}$ The tumor, node, metastasis (TNM) staging system is the most widely used system to classify the anatomical characteristics of CRC propagation. ${ }^{2,5,14,15}$ The established prognostic factors include depth of tumor invasion of the intestinal wall and presence of nodal metastases (most relevant), presence of venous or lymphatic invasion, and the degree of tumor differentiation. ${ }^{16-18}$ Anatomopathological staging of the surgical specimen represents the main tool to be used in isolation to infer the prognosis and survival of patients with $\mathrm{CRC}$, representing the independent dominant variable that most affects survival. ${ }^{18}$ It is also considered the most important prognostic factor, guiding the choice of the ideal cancer treatment. ${ }^{2,15-17}$

Considering that the incidence of CRC is increasing rapidly in low-/middle-income countries, and in view of the essential and desirable diagnostic criteria for CRC, the present study describes and analyzes the clinical and anatomopathological profiles of patients diagnosed with colorectal adenocarcinoma (CRA) who underwent surgical treatment in two hospitals in the state of Paraíba, northeastern Brazil, from 2013 to 2018.

\section{Methods}

\section{Patients}

The present retrospective study included patients diagnosed with CRC identified from 2013 to 2018 at a teaching hospital and a specialized cancer hospital in the state of Paraíba, Brazil. The initial survey of cases was based on the diagnosis of malignant colon, rectosigmoid, and rectal cancers according to the International Statistical Classification of Diseases and Related Health Problems, 10th edition (ICD-10), whose codes for these diseases are C18, C19 and C20 respectively. After the initial survey, we analyzed the clinical and anatomopathological characteristics of the patients diagnosed with CRA who underwent surgical resection. The inclusion criterion was patients treated with curative intent. We excluded selected patients whose pathological reports and/or medical records did not contain satisfactory data. The research was approved by the Committee of Ethics in Research in Human Beings at Hospital Universitário Lauro Wanderley, Universidade Federal da Paraíba, under registration number 03283218.6.0000.5183.

\section{Clinicopathological Data}

The clinical variables were age (subdivided into 5 groups: 19 to 40 years; 41 to 50 years; 51 to 60 years; 61 to 70 years; and $>70$ years) and gender. The anatomopathological parameters evaluated when performing the surgical intervention included: tumor topography (right, left, and rectal); tumor size; histologic type; histological grade; presence of perineural invasion; presence of lymphatic invasion; presence of infiltrating foci in budding pattern (tumor budding); tumor extension/invasion depth (pT); the presence of lymph node metastases $(\mathrm{pN})$; the presence of distant metastases (pM); and the prognostic stage. The staging was carried out according to the Classification of World Health Organization and the TNM classification of the American Joint Committee on Cancer (AJCC). ${ }^{2,19}$

\section{Statistical Analysis}

For the statistical analysis, we used the Statistical Package for the Social Sciences (IBM SPSS Statistics for Windows, IBM Corp., Armonk, NY, United States) software, version 21.0. Statistical significance was defined as $p<0.05$.

\section{Results}

The initial case survey was based on the diagnosis of malignant colon cancer (ICD-10 code: C18), malignant rectosigmoid cancer (ICD-10 code: C19), and malignant rectal cancer (ICD-10 code: C20), totaling 532 cases. Of this total, 71 cases corresponded to non-primary tumors of the colon, rectosigmoid and rectum, and 45 cases (63.4\%) of ovarian serous adenocarcinoma metastases. As for the primary tumors of the colon, rectosigmoid and rectum (461 cases), 9 cases did not correspond to adenocarcinomas (1 gastrointestinal stromal tumor; 2 sarcomas; 2 neuroendocrine tumors; 2 squamouscell carcinomas; and 2 undifferentiated carcinomas). Adenocarcinomas corresponded to $98 \%$ of the CRCs. The final sample was composed of 390 individuals ( 75 cases in 2013; 60 cases in 2014; 57 cases in 2015; 77 cases in 2016; 61 cases in 2017; and 60 cases in 2018), $53.8 \%$ of them female patients.

The average age of the sample was $63.5 \pm 14.00$ years (range: 19 to 97 years), with $81.8 \%$ of individuals aged $>50$ years, and $6.4 \%$ under 40 years of age. In 275 cases (70.5\%), adenocarcinomas were located in distal topography. Rectal adenocarcinomas were observed in 104 (26.6\%) cases. Of the 115 cases (29.5\%) located in the right colon, the cecum was the predominant location. 
Regarding the anatomopathological characteristics, the tumor size averaged $5.2 \mathrm{~cm}$ (range: $0.20 \mathrm{~cm}$ to $20.00 \mathrm{~cm}$ ). Distal tumors had a mean size of $4.7 \mathrm{~cm}$, while proximal adenocarcinomas averaged $6.6 \mathrm{~cm}(p<0.001$ on the Mann Whitney test).

Colorectal adenocarcinoma not otherwise specified (NOS) was observed in $92.3 \%$ of the cases, while mucinous adenocarcinoma, in 7.7\%. Well-differentiated tumors represented only $2.1 \%$ of the cases, followed by cases of poorly-differentiated (6.4\%) and moderately-differentiated (91.5\%) tumors.

As for tumor extension (pT), the following distribution was observed: pT3 status - 71.4\%; pT4 status - $14.3 \%$, with $5.1 \%$ of CRA pT4a and $9.2 \%$ of CRA pT4b; pT2status - $11.5 \%$; pT1 status - $1.8 \%$; and pT in situ - $1 \%$. Perineural invasion was observed in $52.1 \%$ of the cases, angiolymphatic invasion, in $48.7 \%$, and lymph node metastasis, in $46.9 \%$. Distant metastasis was observed in $9.2 \%$ of the cases (of the 36 cases with distant metastasis, 24 corresponded to hepatic metastasis and 12 cases involving the peritoneal cavity). Tumor budding was observed in 106 out of 390 cases (27.2\%).

Localized disease (without lymph node or distant metástases: p-Stage any T, N0, M0) was diagnosed in $51.9 \%$ of patients, and advanced disease (with regional or distant metastases: p-Stage any T, N1-2 or M1), in $48.1 \%$, being $38.7 \%$ of regional regional metastasis.

The absolute and relative frequencies of the clinical and anatomopathological characteristics are shown in - Table 1.

\section{Associations regarding variables}

Lymph-node invasion was more frequent among patients under 60 years of age $(p=0.044)$. We also observed a higher rate of poorly-differentiated adenocarcinomas among women than to men (9.0\% versus $3.3 \%$ respectively). The mucinous histological type was most frequently observed in the right colon (60.0\%). Greater depth of invasion - pT4 status - was observed in $40 \%$ of mucinous adenocarcinomas, and in $12.2 \%$ of adenocarcinomas NOS.

Moderately- and poorly-differentiated (more significantly) CRAs are associated with location in the right colon $(p=0.003)$ and perineural, angiolymphatic, and lymphnode involvement $(p<0.001)$. A poorly-differentiated histological grade was observed in $92 \%$ of the cases of perineural invasion, and in $88 \%$ of the cases of angiolymphatic invasion.

The mucinous histological type, poorly-differentiated histological grade, perineural invasion, angiolymphatic invasion, and lymph-node metastasis were associated with CRAs with pT3 and pT4 status (see - Table 2).

There was a statistically significant association regarding the presence of perineural invasion and the presence of angiolymphatic invasion $(p<0.001)$ and lymph-node metastasis $(p<0.001)$. The detection of angiolymphatic invasion was associated with the presence of lymph-node metastasis and distant metastasis $(p<0.001)$. Patients with positive $\mathrm{pN}$ had distant metastasis $(p<0.001)$. Lymph-node involvement was observed in $88.9 \%$ of the cases with distant metastasis. The presence of distant metastasis (36 cases) was exclusively observed in
Table 1 Absolute and relative frequencies of the clinical and anatomopathological characteristics of the study sample

\begin{tabular}{|c|c|c|}
\hline Variables & $\begin{array}{l}\text { Absolute } \\
\text { value }\end{array}$ & $\begin{array}{l}\text { Percentage } \\
\text { (\%) }\end{array}$ \\
\hline \multicolumn{3}{|l|}{ Gender } \\
\hline Male & 180 & 53.8 \\
\hline Female & 210 & 46.2 \\
\hline Total & 390 & 100 \\
\hline \multicolumn{3}{|l|}{ Age group } \\
\hline 19 to 40 years & 25 & 6.4 \\
\hline 41 to 50 years & 46 & 11.8 \\
\hline 51 to 60 years & 82 & 21.0 \\
\hline 61 to 70 years & 101 & 25.9 \\
\hline$>70$ years & 136 & 34.9 \\
\hline Total & 390 & 100 \\
\hline \multicolumn{3}{|l|}{ Topography } \\
\hline Right side of the colon & 115 & 29.5 \\
\hline Left side of the colon & 171 & 43.8 \\
\hline Rectal & 104 & 27.7 \\
\hline Total & 390 & 100 \\
\hline \multicolumn{3}{|l|}{ Histological type } \\
\hline $\begin{array}{l}\text { Adenocarcinoma not } \\
\text { otherwise specified }\end{array}$ & 360 & 92.3 \\
\hline \multirow{2}{*}{$\begin{array}{l}\text { Mucinous } \\
\text { adenocarcinoma }\end{array}$} & 30 & 7.7 \\
\hline & 390 & 100 \\
\hline \multicolumn{3}{|l|}{ Total } \\
\hline \multicolumn{3}{|l|}{ Histological grade } \\
\hline 1: Well-differentiated & 8 & 2.1 \\
\hline \multirow{2}{*}{$\begin{array}{l}\text { 2: moderately- } \\
\text { differentiated }\end{array}$} & 357 & 91.5 \\
\hline & 25 & 6.4 \\
\hline 3: poorly-differentiated & 390 & 100 \\
\hline \multicolumn{3}{|l|}{ Total } \\
\hline \multicolumn{3}{|l|}{ Tstatus } \\
\hline pT in situ & 4 & 1.0 \\
\hline pT1 & 7 & 1.8 \\
\hline pT2 & 45 & 11.5 \\
\hline pT3 & 278 & 71.4 \\
\hline pT4a & 20 & 5.1 \\
\hline pT4b & 36 & 9.2 \\
\hline Total & 390 & 100 \\
\hline \multicolumn{3}{|l|}{ Tumor budding } \\
\hline Null & 6 & 1.5 \\
\hline No & 278 & 71.3 \\
\hline Yes & 106 & 27.2 \\
\hline Total & 390 & 100 \\
\hline Perineural invasion & 203 & 52.1 \\
\hline Angiolymphatic invasion & 190 & 48.7 \\
\hline Lymph-node metastasis & 183 & 46.9 \\
\hline Distant metastasis & 36 & 9.2 \\
\hline
\end{tabular}


Table 2 Clinico-pathological data and their association with the T status

\begin{tabular}{|c|c|c|c|c|c|c|c|}
\hline \multirow[t]{3}{*}{ Variables } & \multicolumn{5}{|l|}{ T status } & \multirow[t]{2}{*}{ Total } & \multirow[t]{3}{*}{$p$-value ${ }^{a}$} \\
\hline & pT1 & pT2 & pT3 & pT4 & pT in situ & & \\
\hline & $N(\%)$ & $N(\%)$ & $N(\%)$ & $N(\%)$ & $N(\%)$ & $N(\%)$ & \\
\hline \multicolumn{8}{|l|}{ Histological type } \\
\hline $\begin{array}{l}\text { Adenocarcinoma not } \\
\text { otherwise specified }\end{array}$ & $6(85.7)$ & $45(97.8)$ & $261(94.2)$ & $44(78.6)$ & $4(100.0)$ & $360(92.3)$ & \multirow[t]{2}{*}{$0.004^{*}$} \\
\hline Mucinous adenocarcinoma & $1(14.3)$ & $1(2.2)$ & $16(5.8)$ & $12(21.4)$ & $0(0.0)$ & $30(7.7)$ & \\
\hline \multicolumn{8}{|l|}{ Histological grade } \\
\hline 1: well-differentiated & $2(28.6)$ & $2(4.3)$ & $1(0.4)$ & $0(0.0)$ & $3(75.0)$ & $8(2.1)$ & \multirow[t]{3}{*}{$<0.001^{*}$} \\
\hline 2: moderately-differentiated & $5(71.4)$ & $44(95.7)$ & $260(93.9)$ & $47(83.9)$ & $1(25.0)$ & $357(91.5)$ & \\
\hline 3: poorly-differentiated & $0(0.0)$ & $0(0.0)$ & $16(5.8)$ & $9(16.1)$ & $0(0.0)$ & $25(6.4)$ & \\
\hline \multicolumn{8}{|l|}{ Perineural invasion } \\
\hline No & $7(100.0)$ & $37(80.4)$ & $125(45.1)$ & $13(23.2)$ & $4(100.0)$ & $186(47.7)$ & \multirow[t]{3}{*}{$<0.001^{*}$} \\
\hline Yes & $0(0.0)$ & $9(19.6)$ & $152(54.9)$ & $42(75.0)$ & $0(0.0)$ & $203(52.1)$ & \\
\hline Null & $0(0.0)$ & $0(0.0)$ & $0(0.0)$ & $1(1.8)$ & $0(0.0)$ & $1(0.3)$ & \\
\hline \multicolumn{8}{|l|}{ Angiolymphatic invasion } \\
\hline No & $7(100.0)$ & $37(80.4)$ & $139(50.2)$ & $13(23.2)$ & $4(100.0)$ & $200(51.3)$ & \multirow[t]{2}{*}{$<0.001^{*}$} \\
\hline Yes & $0(0.0)$ & $9(19.6)$ & $138(49.8)$ & $43(76.8)$ & $0(0.0)$ & $190(48.7)$ & \\
\hline \multicolumn{8}{|l|}{ Lymph-node invasion } \\
\hline No & $6(85.7)$ & $36(78.3)$ & $135(48.7)$ & $21(37.5)$ & $1(25.0)$ & $199(51.0)$ & \multirow[t]{3}{*}{$<0.001$} \\
\hline Yes & $0(0.0)$ & $8(17.4)$ & $141(50.9)$ & $34(60.7)$ & $0(0.0)$ & $183(46.9)$ & \\
\hline Null & $1(14.3)$ & $2(4.3)$ & $1(0.4)$ & $1(1.8)$ & $3(75.0)$ & $8(2.1)$ & \\
\hline
\end{tabular}

Notes: 'Likelihood ratio test; *statistically significant $(p<0.05)$.

adenocarcinomas with depth of invasion: pT3 status $-75 \%$ of the cases, and pT4 status $-25 \%$ of the cases $(p=0.025)$.

Tumor budding were associated with the female gender $(p=0.026)$, mucinous tumors $(p=0.037)$, angiolymphatic invasion $(p<0.001)$, and positive lymph-node staging $(p<0.001)$. Regarding the T status, the presence of tumor budding was more frequently observed in adenocarcinomas with greater depth of invasion: pT3 (83 out of 106 cases with budding) and pT4 (20 out of 106 cases with budding).

Between 2013 and 2018, there were no changes regarding average tumor size $(p=0.283)$, the topography of the neoplasia $(p=0.687)$, or the distribution among age groups $(p=0.345)$.

\section{Discussion}

In the present study, $98 \%$ of the primary tumors of the colon, rectosigmoid and rectum corresponded to adenocarcinomas, which is in line with the worldwide prevalence of $90 \%{ }^{2}$

Colorectal cancer is the second most common cancer among women and the third most common cancer among men. ${ }^{2,9,10,20}$ In the present study, there was a slight prevalence of colorectal adenocarcinoma among women (53.88\%), a situation that may be related to the introduction of population screening, 2,12 as it is known that women are more assiduous and connected with health care, ${ }^{12}$ thus increasing the number of diagnosed cases. In addition, women tend to pay more attention to their illness processes that involve the perception and report of health conditions. Men have less varied eating habits and higher alcohol consumption compared to women; therefore, men present a higher frequency of unhealthy behaviors. ${ }^{21}$ It is important to highlight that, in the present study, female patients had a higher rate of poorly-differentiated adenocarcinomas compared to male patients (9.0\% against 3.3\% respectively).

The average age of the sample was 63.5 years, slightly lower than the average age of 65 years reported by Pestana and Martins ${ }^{4}$ in a study conducted in a underdeveloped country and the average age of 71 years reported by Glover et al. ${ }^{12}$ in a study conducted in a developed country. CRA was diagnosed in individuals over 50 years of age in 81.8 of the cases. In the United States $90 \%$ of cases are diagnosed for this same age group. ${ }^{1,4,11}$ The high prevalence in individuals older than 50 years of age confirms that CRC is a disease of the elderly, ${ }^{4}$ whose incidence increases continuously with age, especially after 50 years. ${ }^{1,6,11}$ In the present study, the frequency of CRC in the age group $<40$ years $(6.4 \%, 25$ of 390 cases) observed was closer to rates reported in the literature for developed countries ( $2 \%$ to $8 \%)^{4}$ than the rates reported for underdeveloped and emerging countries (15\% to 35\%). ${ }^{13}$

According to the literature, ${ }^{2}$ most colorectal cancers are located in the left side of the colon or are rectal cancers. In 
the present study, 275 cases (70.5\%) of adenocarcinomas were located in the left side of the colon. The most prevalent diagnosis for colorectal cancer located on the left is related to higher frequency of bleeding for these tumors, which may lead to more screening in the population, or even greater adoption of screening strategies, including fecal occult blood tests, which are more sensitive to neoplasms of the tumor left side.,11

In addition, the diagnostic accuracy decreases in proximal tumors, contributing to delays in diagnosis and treatment. ${ }^{12}$ In turn, larger tumors on the right side are eventually found in late diagnoses, as was the case of the present research and of a previous study ${ }^{17}$ also conducted in a developing country.

In the present study, the most common histological subtype (mucinous adenocarcinoma) was observed in $7.7 \%$ (30 of 390 cases) of the cases, which is in line with the worldwide prevalence, which ranges from $5 \%$ to $20 \%{ }^{2}$ In the present study, mucinous tumors were associated with greater depth of invasion (pT4 status), and perforation of the visceral peritoneum or invasion/adherence to adjacent organs or structures may lead to metastatic dissemination by direct implantation in the peritoneal cavity. According to previous studies, ${ }^{2}$ there is no prognostic difference compared with adenocarcinoma NOS, although there is a relatively poor response of mucinous tumors to systemic treatment in the metastatic setting.

In the present series, more advanced degrees of differentiation were associated with prognostic factors of aggressiveness such as perineural invasion, angiolymphatic invasion, and lymph-node metastasis. For poorly-differentiated CRAs, the frequency of perineural and angiolymphatic invasion was $>90 \%$. These associations are also found in the literature; ${ }^{18,22}$ thus, a more reserved prognosis is attributed to moderately- and poorly-differentiated tumors.

Tumor extension through the intestinal wall had advanced status (pT3 and pT4) in $85.7 \%$ of cases, a rate higher than that ound by Pescatore et al. ${ }^{23}$ in a study conducted over the course of 20 years in a developed country ( $76 \%$ of cases of CRC in stages PT3 and pT4). The numbers show that CRAs are still being diagnosed in advanced stages ${ }^{24}$ regarding penetration in the intestinal wall. Consequently, this histological parameter contributes to the smaller number of localized diseases.

The $\mathrm{T}$ status has been identified as an independent survival prognostic factor, and it is associated with a higher risk of tumor recurrence. ${ }^{2,17,18}$ Depth of invasion in combination with other prognostic factors, such as degree of differentiation, presence of invasion lymph-node and tumor sprouting, is related to the risk of lymph-node metastasis., 2,18 In the present study, stages pT3 and pT4 were associated with prognostic factors of aggressiveness such as poorlydifferentiated histological grade, perineural invasion, angiolymphatic invasion, lymph-node metastasis, and distant metastasis, which is known to compromise prognosis and survival. ${ }^{1,2,5-7,15}$

Perineural invasion, which is a negative prognostic factor that indicates a specially-aggressive carcinoma, ${ }^{19}$ was present in $52.1 \%$ of cases in the present study, a rate much higher than that reported in other studies $(20 \%){ }^{2,19}$ There is an increased incidence of this histological finding in tumors in more advanced stages and in the presence of other risk factors, such as vascular and lymphatic invasion, ${ }^{2}$ which was duly observed in the present study. Angiolymphatic invasion also represented in our sample a morphological risk factor for the presence of lymph-node metastasis, ${ }^{2}$ constituting an independent indicator of adverse prognosis. ${ }^{19}$

An examination of the compromised lymph nodes is considered the most relevant procedure in the anatomopathological analysis of operative specimens of CRAs, since it is one of the most important and independent factors related to prognosis and therapeutic conduct. ${ }^{18,25}$ Patients with lymph-node metastasis present a shorter rate of survival and need systemic adjuvant chemotherapy. ${ }^{25,26}$ In the present study, lymph-node involvement was associated with distant metastasis, which results in a more reserved prognosis. In addition, we highlight the association found in the present series, in which most cases of lymph-node invasion affected patients younger than 60 years of age.

Tumor budding is considered the morphological manifestation of the epithelial-mesenchymal transition, which is associated with adverse prognostic characteristics and poor results in several types of CRC. ${ }^{2}$ Tumor budding is associated with higher TNM stage, high tumor grade, presence of lymphovascular invasion and, consequently, nodal and distant metastases. ${ }^{27}$ The associations found in the present study (with angiolymphatic invasion, positive lymph-node staging, and greater depth of invasion) reinforce the findings recently described in the literature. In the present research, tumor budding was also associated with the female gender and mucinous tumors.

Our failure to observe changes over the six years analyzed in the present study in relation to tumor topography or distribution across age groups differ from CRC trends reported in more recent studies conducted in developed countries, which indicate an increased rate of diagnosis of tumors located on the right side of the colon and in younger patients. ${ }^{1-3,5,6,12,19,24,28,29}$

Such trends are related to the establishment, dissemination and effectiveness of screening programs in high-income countries. ${ }^{2}$ In low- and middle-income countries, the most frequent patterns observed in non-early diagnoses still prevail (which indicates the absence of screening), and the diagnosis of CRC is more commonly made in the elderly and when the patients present symptoms. Thus, these patients are diagnosed with more advanced tumors, which, consequently, may indicate diseases in a more advanced stages, with lymph-node metastasis (regional disease), leading to a more aggressive treatment, with greater damage and higher costs.

Between 2013 and 2018, the occurrence of regional disease in the present study (38.7\%), was higher than that observed by Siegel et al. ${ }^{30}$ among Americans between 2000 and 2012 (34.5\%). Thus, the diagnosis of the disease in advanced stages is still a reality, which affected in almost half of the patients in the present study (48.1\%), which was conducted in the Northeastern Region of Brazil, where the incidence of CRC is the second lowest in the country (2.8-fold lower compared to that of other regions). ${ }^{8}$ 
If, on the one hand, the lower exposure of this population to factors related to higher risks of developing CRC (dietary habits that increase the risk, for example) and underreporting are related to the lower incidence, ${ }^{31,32}$ on the other hand, a scenario of difficult access to screening for early detection and treatment of cancer, associated with a limited health infrastructure, favors and reinforces the pattern of late diagnosis and aggressive disease. As the probability of survival in CRC depends considerably on the stage of the disease at diagnosis, and the treatment is based on multiple modalities depending on the extent of the cancer, the possibility of cure is diminished, with a more reserved prognosis.

\section{Conclusion}

At the time of the diagnosis and anatomopathological analysis, the cases of CRC showed greater depth of invasion and more advanced stages in more than half of the sample of the present study. Considering that a high incidence of CRC is consistently observed in populations with the typical diets of high-income countries combined with a sedentary lifestyle, and that the adoption of this same lifestyle pattern is ongoing in poor countries, urgent and effective actions are highly recommended, such as adopting preventive measures and screening strategies, thus enabling early diagnosis and treatment of CCR in low- and middle-income countries.

\section{References}

1 Siegel RL, Miller KD, Goding Sauer A, et al. Colorectal cancer statistics, 2020. CA Cancer J Clin 2020;70(03):145-164

2 Nagtegaal ID, Odze RD, Klimstra D, et al; WHO Classification of Tumours Editorial Board. The 2019 WHO classification of tumours of the digestive system. Histopathology 2020;76(02):182-188

3 González N, Prieto I, Del Puerto-Nevado L, et al; DiabetesCancerConnect Consortium. 2017 update on the relationship between diabetes and colorectal cancer: epidemiology, potential molecular mechanisms and therapeutic implications. Oncotarget 2017;8 (11):18456-18485

4 Pestana JSG, Martins SFF. Colorectal cancer: comparative analysis of clinical and pathological characteristics in patients aged above and below 45 years of age and impact on prognosis. J Coloproctol (Rio J) 2016;36(04):196-202

5 Karamchandani DM, Chetty R, King TS, et al. Challenges with colorectal cancer staging: results of an international study. Mod Pathol 2020;33(01):153-163

6 Araghi M, Soerjomataram I, Jenkins M, et al. Global trends in colorectal cancer mortality: projections to the year 2035. Int J Cancer 2019;144(12):2992-3000

7 Aran V, Victorino AP, Thuler LC, Ferreira CG. Colorectal Cancer: Epidemiology, Disease Mechanisms and Interventions to Reduce Onset and Mortality. Clin Colorectal Cancer 2016;15(03): 195-203

8 Santos Mde OEstimativa/2020-Incidência de Câncer no Brasil. Rev Bras Cancerol 2020;66(01):e00927

9 Leung WK, Chen W-Q, Gu L, Long D, Law WL. Distributions of colorectal cancer in two Chinese cities with contrasting colorectal cancer epidemiology. J Gastroenterol Hepatol 2015;30(12): $1726-1730$

10 Lee DH, Keum N, Giovannucci EL. Colorectal Cancer Epidemiology in the Nurses' Health Study. Am J Public Health 2016;106(09): 1599-1607
11 Rawla P, Sunkara T, Barsouk A. Epidemiology of colorectal cancer: incidence, mortality, survival, and risk factors. Prz Gastroenterol 2019;14(02):89-103

12 Glover M, Mansoor E, Panhwar M, Parasa S, Cooper GS. Epidemiology of Colorectal Cancer in Average Risk Adults 20-39 Years of Age: A Population-Based National Study. Dig Dis Sci 2019;64(12): 3602-3609

13 Marley AR, Nan H. Epidemiology of colorectal cancer. Int J Mol Epidemiol Genet 2016;7(03):105-114

14 Mesker WE, Junggeburt JMC, Szuhai K, et al. The carcinomastromal ratio of colon carcinoma is an independent factor for survival compared to lymph node status and tumor stage. Cell Oncol 2007;29(05):387-398

15 Brenner H, Kloor M, Pox CP. Colorectal cancer. Lancet 2014;383 (9927):1490-1502

16 Mahar AL, Compton C, Halabi S, Hess KR, Weiser MR, Groome PA. Personalizing prognosis in colorectal cancer: A systematic review of the quality and nature of clinical prognostic tools for survival outcomes. J Surg Oncol 2017;116(08):969-982

17 Pereira Júnior T, Alves AJ, Nogueira AMMF. Câncer colorretal: análise anatomopatológica de 476 colectomias consecutivas em Belo Horizonte (MG). J Bras Patol Med Lab 2005;41(03):175-184

18 Volpato MG, Koch Kde SFatores de mau prognóstico nas peças operatórias de pacientes submetidos ao tratamento cirúrgico do câncer colorretal. Rev Bras Coloproctol 2008;28(04):414-424

19 Amin MBAmerican Joint Committee on Cancer, American Cancer Society. editors. AJCC cancer staging manual. Eight edition / editor-in-chief, Mahul B. Amin, MD, FCAP; editors, Stephen B. Edge, MD, FACS [and 16 others]; Donna M. Gress, RHIT, CTRTechnical editor; Laura R. Meyer, CAPM-Managing editor. Chicago IL: American Joint Committee on Cancer, Springer; 2017

20 Santos Mde OEstimativa 2018: Incidência de Câncer no Brasil. Rev Bras Cancerol 2018;64(01):119-120

21 Gasparini B, Valadão M, Miranda-Filho A, Silva CMFPD. [Analysis of the age-period-cohort effect on mortality from colorectal cancer in Rio de Janeiro State, Brazil, from 1980 to 2014]. Cad Saude Publica 2018;34(03):e00038017

22 Saad-Hossne R, Prado RG, Bakonyi Neto A, et al. Estudo retrospectivo de pacientes portadores de câncer colorretal atendidos na Faculdade de Medicina de Botucatu no período de 2000-2003. Rev Bras Coloproctol 2005;25(01):31-37

23 Pescatore P, Scheiden R, Abeywickrama KH, Braun M, Capesius C. Evolution of colorectal cancer epidemiology in a setting of opportunistic screening. A 20 year national survey in Luxembourg. Acta Gastroenterol Belg 2013;76(01):25-33

24 Valadão M, Leal RA, Barbosa LC, Carneiro M, Muharre RJ. Perfil dos pacientes portadores de câncer colorretal operados em um hospital geral: necessitamos de um programa de rastreamento acessível e efetivo. Rev Bras Coloproctol. 2010;30(02):160-166

25 Cserni G. Nodal staging of colorectal carcinomas and sentinel nodes. J Clin Pathol 2003;56(05):327-335

26 Bowel cancer statistics [Internet]. Cancer Research UK. 2017 [cited 2020 Oct 27]. Available from: https://www.cancerresearchuk org/health-professional/cancer-statistics/statistics-by-cancer-type/ bowel-cancer

27 Lugli A, Kirsch R, Ajioka Y, et al. Recommendations for reporting tumor budding in colorectal cancer based on the International Tumor Budding Consensus Conference (ITBCC) 2016. Mod Pathol 2017;30(09):1299-1311

28 Wang W, Chen W, Lin J, Shen Q, Zhou X, Lin C. Incidence and characteristics of young-onset colorectal cancer in the United States: An analysis of SEER data collected from 1988 to 2013. Clin Res Hepatol Gastroenterol 2019;43(02):208-215

29 Valle L, Vilar E, Tavtigian SV, Stoffel EM. Genetic predisposition to colorectal cancer: syndromes, genes, classification of genetic variants and implications for precision medicine. J Pathol 2019; 247(05):574-588 
30 Siegel RL, Miller KD, Fedewa SA, et al. Colorectal cancer statistics, 2017. CA Cancer J Clin 2017;67(03):177-193

31 de Oliveira MM, Latorre M, Tanaka LF, Rossi BM, Curado MP. Disparidades na mortalidade de câncer colorretal nos estados brasileiros. Rev Bras Epidemiol. 2018;21:e180012
32 de Andrade Pullig E, Garcia Cunha Lopes G, Porto Magalhães Netto G, Moreira Ribeiro J, Amorim Silva L, Lima De Moraes Morué N Câncer colorretal no Brasil: aspectos topográficos e epidemiológicos (2000-2011). 2019 Jul [cited 2021 May 27]; Available from: http://repositorio.aee.edu.br/jspui/handle/aee/1365 